\title{
A Comprehensive, Research-based, Peer Review and Self-evaluation Module for Integration into Combined Composition Classes for Second (L2) and Heritage (HL) Language Learners of Spanish
}

\author{
John M. Ryan \\ University of Northern Colorado, USA
}

\begin{abstract}
Second (L2) and heritage (HL) language learners face a variety of similar challenges when they approach the writing of Spanish compositions. Practitioners have often suggested peer editing as a prefinal step to help identify student writing errors that can be corrected before submission of a final product. However, some studies reveal that student writers do not always trust feedback from their classmates and hesitate to follow through with peer recommendations to the same extent they will from their instructors. This paper suggests an enhancement to the traditional peer editing process that combines a semester-long training program in peer and self-evaluation along with a research-based instrument for a more comprehensive evaluation of Spanish compositions. The instrument is versatile enough to serve students who place at different levels of proficiency along both $\mathrm{L} 2$ and HL learner continuums. The paper argues that by becoming a better peer evaluator, one in turn becomes a better self-evaluator. This new process returns control to students, creates more self-reliant writers, and empowers them to significantly improve their essays prior to submission. The paper concludes with the suggestion that if students adopt this process and continue its use it for future compositions, they can eventually become sufficiently trained to the point at which application of evaluation criteria becomes part of their normal mental routine before submitting any written work.
\end{abstract}

Index Terms - composition studies, peer review, Spanish, heritage learners, second language learners

\section{INTRODUCTION}

Whether it is your first or second language, writing can be a highly prescribed form of expression, based on norms established by society or a linguistic community. In contrast, most oral speech occurs in the moment, is haphazard in nature, characterized by stops and starts, and with little concern if any for word choice, grammaticality, or complexity. Writing, on the other hand, is intended to be read after the time at which it is composed, and the writer theoretically has more time to spend on such elements as word choice, spelling, or grammar. The down side of written work is that expectations are usually much higher than those for oral speech, and therefore, it takes much longer to produce, and when graded, undergoes much closer scrutiny. Such essential differences between speaking and writing are precisely what make these unique and distinct skills to acquire in both L1 and L2 contexts.

\section{PuRpose AND ORganization OF This PAPER}

In 2017-2018, I conducted a study of composition errors from a class of fifteen students, from both heritage (HL) and non-heritage (L2) backgrounds, and between whom I compared the frequencies of 30 error types over a semester's time with the writing of five essays (Ryan 2018). In addition to analyzing the data, a second purpose of that study was to devise strategies and recommendations for instructors on how to address the different needs of the two populations in a single classroom setting. As a matter of practicality and for limitations of space, the errors presented in Ryan (2018) were restricted to those occurring in both groups with moderate to high frequency. This being said, it was always my intention to write a second paper that would focus on the student more than the teacher. It is therefore the purpose of the present article to provide a more comprehensive matrix of the word and sentence level error types found among the original fifteen student participants of the 2017-2018 study, and to propose a new peer review and self-evaluation module that can be incorporated into the student writing process, so that future L2s and HLs, as well as their peer reviewers, may take a more proactive stance in improving their compositions before ultimately turning them in for a grade. $^{1}$

\footnotetext{
${ }^{1}$ In Ryan (2018), heritage learners were represented by the expression "L1" in order to distinguish them from second language learners, who in that same study were represented as "L2." This simplified dichotomy was adequate for purposes of that paper since no distinctions were made, as will be made here, among first (L1), second (L2), and heritage (HL) language learners.
} 
The remainder of this paper is organized as follows. First, I will present the literature that has been conducted on the utility and effectiveness of instructor and peer feedback on L2 student compositions. The next section, titled "Discussion," is the largest of the paper, and comprises three sub-components: 1) an explanation of the L1/HL/L2 learner spectrum or continuum; 2) the matrix of possible L2/HL learner composition errors; and 3) a case for the "active" writing of Spanish compositions, including a proposal for integration of a "Peer Review and Self-Evaluation" module. The final section of the paper offers the conclusions of this study. ${ }^{2}$

\section{PRIOR RESEARCH}

The topic of writing L2 compositions, as well as that of error analysis of said compositions, are amply represented among the research. ${ }^{3}$ More specifically, work on the effectiveness and utility of either teacher or peer feedback has also appeared in abundance, although the results of such studies are not conclusive. In terms of teacher assessments, work by Hyland \& Hyland (2006) suggests that teachers are challenged with multiple tasks when grading student compositions, and this, coupled with the desire to maintain a positive working relationship may affect both the effectiveness and level of feedback. While Truscott (2007) suggests that observations of student improvement may not always correlate to acquisition of a given structure, Ferris (2004) maintains that such studies are inconclusive. Another strand of research has focused on the impacts of peer editing as part of the writing process. A study by Brinkman (2003) examined the nature of peer feedback on L2 Spanish compositions and found that comments from classmates focused more on errors in spelling, and less so on grammar or content. However, issues of variability in the adequacy of student peer proficiency or the level of discipline of student assessments calls into question the ultimate effectiveness and reliability of such a component. Another limitation of this approach is that it is not always available to the student writer, once students are no longer in the composition class, access to peer proof readers may be limited. Conversely, other studies suggest that the peer editing process may have beneficial secondary effects on student writing. According to Liu and Hansen (2002), the peer review process may be more helpful than harmful to students in that it can help them see how others view their work. Hyland and Hyland (2006) suggest that participation in peer evaluation activities gives confidence and a sense of autonomy (Chaudron 1984; Cotterall and Cohen 2003). In more general terms, according to Nas and van Esch (2014), it should be any instructor's goal for students to become "more critical evaluators of their own writing." This paper undertakes this challenge with a proposal to improve both peer review and self-evaluation.

\section{DisCUSSION}

\section{The L1/HL/L2 Learner spectrum/continuum}

As suggested by Ryan (2018), heritage students are not all cut of the same cloth linguistically, and the extent of both speaking and writing proficiency can vary according to an individual learner's circumstances. ${ }^{4}$ Figure 1 illustrates a potential model for the variances that can appear in heritage language production by four hypothetical heritage language speakers, labeled here as $\mathrm{HL}^{1}, \mathrm{HL}^{2}, \mathrm{HL}^{3}$ and $\mathrm{HL}^{4}$

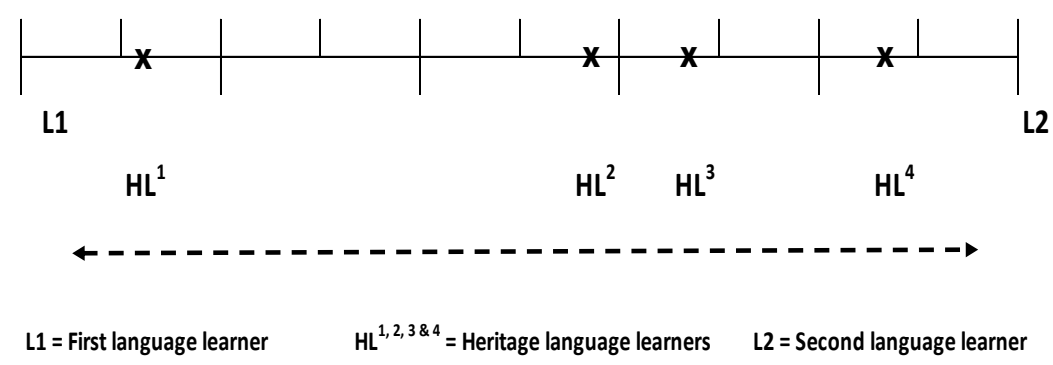

Figure 1: Heritage language learner spectrum or continuum

Figure 1 shows how, depending on the extent of prior and continued exposure to the language, a heritage learner's language production can vary anywhere between L1 and L2 production (as indicated by the different x's along the continuum). For example, in some cases HL output may resemble more closely what a native or L1 speaker/learner would produce, as indicated by the proximity of hypothetical heritage language learner $\mathrm{HL}^{1}$ to $\mathrm{L} 1$ in the figure, while in other cases, language production by other heritage learners who may not have mastered the conventions of writing or

\footnotetext{
${ }^{2}$ The publication of this article was supported by the University of Northern Colorado Fund for Faculty Publications and a portion of the research with a 2017 UNC Summer Support Initiative Award No. QS232.

${ }^{3}$ For research related to error analysis both in Spanish and other languages, I refer the reader to the "Prior research" section of Ryan (2018).

${ }^{4}$ Ryan (2018) suggests that the writing ability of a particular heritage learner has much to do with such factors as how much previous formal education in the language the student has had, the age the student has immigrated (if relevant), how much Spanish written content is available to the student on a daily basis, where the student falls within the family in relation to older or younger siblings, and how much Spanish is spoken with them, etc.
} 
have been heavily influenced by transfer from another language they have been exposed to (Camacho (2018), as in the hypothetical cases of $\mathrm{HL}^{2}$ and $\mathrm{HL}^{3}$, may exhibit significantly more errors than $\mathrm{HL}^{1}$. Lastly, yet another category of heritage learner, represented here as $\mathrm{HL}^{4}$, and who has had minimal exposure to Spanish, may produce language output resembling more that which is typical of an L2 speaker/learner. These differences are important to keep in mind when considering the wide variety of possible errors that are presented here to have been observed in both learner populations.

\section{Heritage and non-heritage learner errors: What's the same? What's different?}

One of the central points made in Ryan (2018) was the observation that both non-heritage and heritage students of that study frequently made the same types of errors throughout the semester, though in different distributions. Figure 2 , reproduced here from Ryan (2018), compares the overall percentage distribution of word errors that were identified for both heritage and non-heritage students of that study.

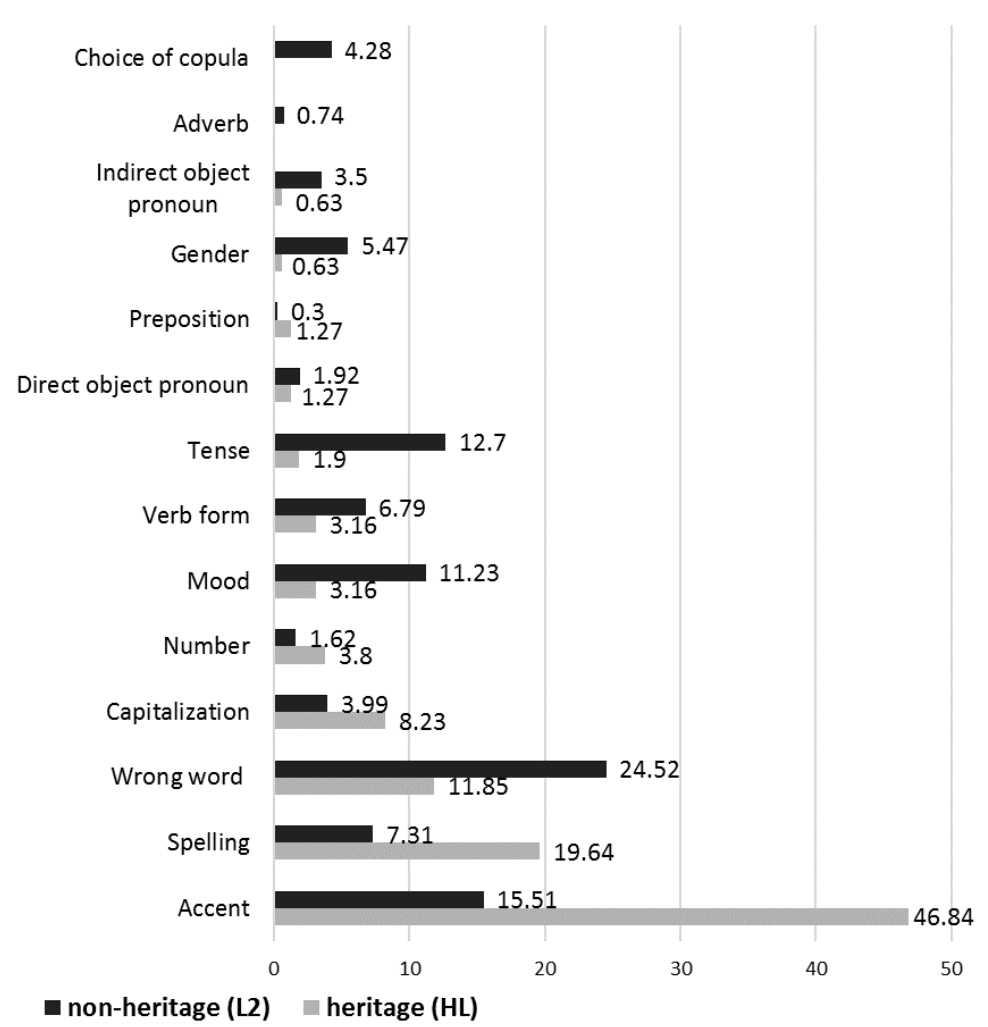

Figure 2: Comparative percentage distribution of overall L2 and HL word-level errors (Ryan 2018)

Figure 2 confirms that although word-level errors were committed to different degrees between heritage and nonheritage students, most were found to occur in both groups, and some at rates ranging from moderate to high frequency. ${ }^{5}$ The figure shows that errors in the use of accents, word choice, and spelling were the most common for both groups, followed by those of capitalization, verb form, and mood. Figure 2 also shows that errors involving copula choice and adverb usage were committed exclusively by L2 students, and that although heritage speakers also committed a small number of errors in terms of gender and pronoun use, these were more often committed by L2 students.

Figure 3 shows the percentage frequency of sentence-level errors among students of the Ryan (2018) study illustrating that, with the exception of subject pronoun redundancy, both heritage and non-heritage learners, as was the case for word-level errors, once again exhibit the same types of errors, but in different proportions.

\footnotetext{
${ }^{5}$ Moderate frequency is defined here as over $5 \%$ occurrence, while high frequency is defined as over $10 \%$.occurrence.
} 


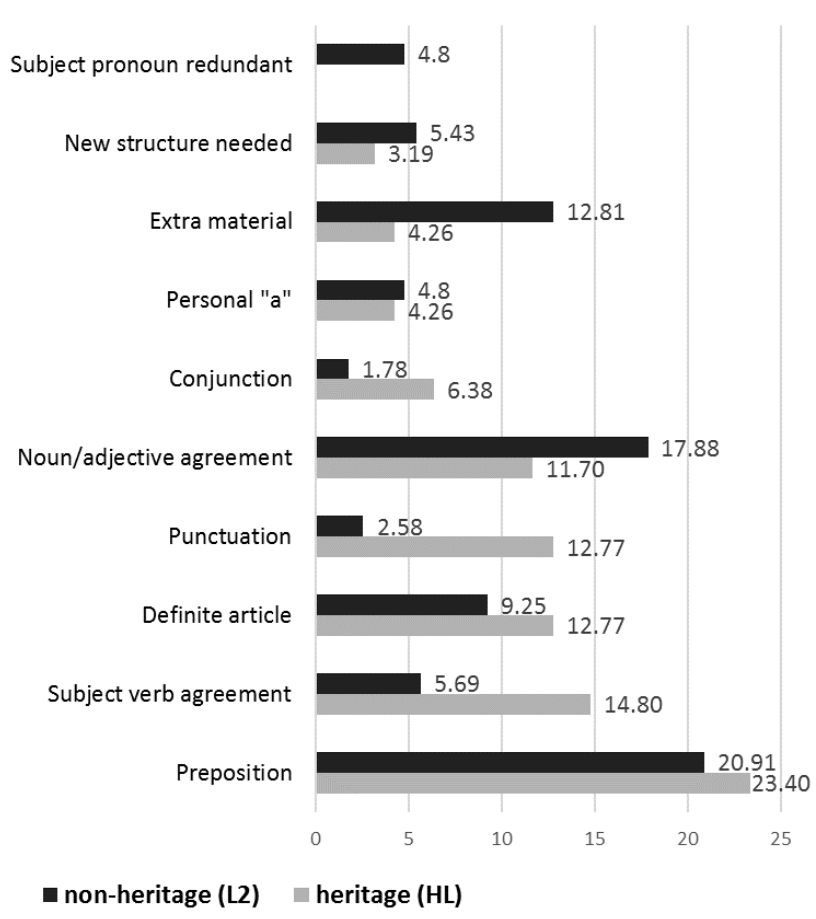

Figure 3: Comparative percentage distribution of overall L2 and HL sentence-level errors (Ryan 2018)

Figure 3 shows that faulty preposition use is the most prevalent error at the sentence level for both L2 and HL students, followed by errors of agreement (both nominal and verbal), as well as the definite article. Other less problematic items for both groups, yet existing nonetheless, were inadequate conjunction usage, the personal "a", erroneous structure, unnecessary additional material, and punctuation deficiencies. Only L2 students were found to overuse subject pronouns when unnecessary.

Matrix of L2/HL Learner Composition Errors

This section takes a deeper look at Spanish learner errors and the extent to which they have been found to be similar or different between each population.

\section{A. Transfer Errors (Typical among Second Language Learners and Some Heritage Learners)}

Second language learners of Spanish, particularly those who are first language speakers of English and are newer writers of Spanish, tend to make the following errors that are more grammatical in nature, primarily because the structures they must form in Spanish are things that we just do not do in English. Such errors tend to have to do with agreement, the misuse or omission of prepositions, and the unfamiliarity with Spanish-specific rules regarding null subjects or differential object marking, all because these are handled so differently in English.

1. Errors of agreement

a. Noun-adjective agreement-Because of the large number of nouns that typically occur in a sentence as compared to any of the other lexical parts of speech, one of the most common and numerous composition errors found in Ryan (2018) for English speakers learning Spanish, was the lack of agreement between nouns and their modifiers, these being adjectives and determiners. Because these forms are not inflected in English, it is not surprising that a second language learner whose priority is that of communicating the meaning of a form, pays secondary attention to the inflection of the form. An example of this would be the incorrect target of the utterance 'a pretty house' as *un casa bonito, the correct form being una casa bonita. Another complicating factor of noun-adjective agreement is that some Spanish nouns are not as transparent as others in terms of their gender, especially when these end in a consonant or have a specialized etymology, which in turn give rise to some students using the wrong article (e.g., *la huracán instead of el huracán). Some heritage students who lie somewhere more toward the middle of the L1-HL-L2 end of the spectrum, and typical of our hypothetical $\mathrm{HL}^{2}$ or $\mathrm{HL}^{3}$ speaker in Figure 1, have also been observed to misgender more obscure nouns as in *la problema because of the final - $a$, typical of feminine nouns, with the correct form being el problema 'the problem,' which is masculine due to its Greek, and not Latin, origin.

b. Subject-verb agreement-Another common composition error found in Ryan (2018) for second language and some heritage learners in Spanish was the lack of agreement between the verb and its subject. Because we almost never do this in English, only in the third person singular of the present tense and in the present tense of the verb to be, the lack of this type of agreement is also typical of the transfer type error. For example, in English the subjects I/you/we/they all take the same verb form (i.e., "study"), whereas in Spanish these same subjects all take different inflections of the verb form (e.g, yo estudio, tú estudias, nosotros estudiamos, vosotros estudiáis, and ellos estudian). This is further complicated by the fact that all other Spanish tenses are fully inflected as well. 


\section{Prepositional errors}

a. Unnecessary prepositions -In English we sometimes use the preposition "of" after the word "all," as in "all of my friends," or "all of my work," however, in Spanish one NEVER uses the equivalent preposition de in this same way. For example, one would never say *todos de mis amigos or *todo de mi trabajo. You can ONLY say todos mis amigos or todo mi trabajo. Another example is the overuse of para 'for', or in this case 'to'. Students often do this when they have to use the infinitive in Spanish and because the English infinitive consists of the sequence 'to + bare verb form', they feel it necessary to supply para before the Spanish infinitive as well. The problem here is that the Spanish infinitive is a self-contained single word. Examples of such a transfer error are the expressions Es dificil para trabajar. 'It is difficult to work' or Es fácil para manejar 'It is easy to drive'. Additionally, some verbs in English behave differently from Spanish when it comes to prepositions that are required after a verb. For example, the preposition $a$ is always required after the verb ayudar. "to help (someone) do (something)" ayudar a hacer (algo).

b. Missing or incorrect prepositions-Another example is the verb soñar 'to dream' that requires the preposition con 'with,' whereas in English "dream" requires the preposition "of" or "about." Additionally, the prepositions por and para, both meaning 'for' in Spanish are typically confused by students because of the fact that English has only one equivalent corresponding to both words.

\section{Subject and object marking}

a. Subject pronouns-Spanish, being a null-subject language, does not require subject pronouns as does English. In fact, the overuse of pronouns in Spanish makes a composition sound redundant and non-native-like. Ryan (2018) has observed that only the second language learners and none of the HLs of the study overused pronouns.

b. Personal " $a$ "-In English we treat direct objects the same whether they are animate or not. In Spanish, however, direct objects that refer to people or pets are usually preceded by the particle $a$.

c. Definite articles-Definite articles (el, la, los, and las) are used much more often in Spanish than they are in English. English speakers who are writing in Spanish often leave out definite articles when speaking of things in general, but they are required. Notice how Spanish and English are so different in this respect. ¿Te gusta el pan? 'Do you like bread?' or La gente dice... 'People say...' Students tend to transfer the English tendency when writing Spanish so they would write ${ }^{*}$ Te gusta pan? or simply, ${ }^{*}$ Gente dice., both without the definite article which in turn would make them incorrect.

4. Other transfer errors

a. Incorrect pronouns of address (and/or maintaining these throughout a text)-Whereas English employs a single pronoun of address, "you," standard Spanish, on the other hand utilizes two pronouns of address, tú for informal contexts, and usted (abbreviated as $V d$. or $U d$.) for more formal occasions. L2 students have been observed to overuse the $t u$ form regardless of the one that is required in Spanish. Yet another tendency is for L2 learners to alternate the use of the two forms within the same document, as in a cover letter or other business correspondence, where the informal pronoun would never be used.

b. Copula choice-Spanish uses three different verbs to express the different uses of the English verb "to be." These are ser (for more permanent qualities), estar (for temporary qualities or states), and haber (in the existential sense). L2 students tend to overuse ser in capacities where the other two verbs are required.

c. Missing relative pronouns or conjunctions - In larger or complex sentences in English, we can often omit the word "that" when used as a relative pronoun or conjunction, however, in Spanish the word que in these circumstances is absolutely necessary. So, in English where it is permissible to say, "I know you have to go." in Spanish you would have to say the equivalent of "I know that you have to go." Or Sé que te tienes que ir.

d. Word order--Oftentimes, students need reminding that certain word orders in English do not hold true for Spanish. For example, attributive adjectives tend to follow nouns in Spanish more often than they precede them. In fact, in cases where they precede the noun, they usually have a more specialized meaning (e.g., mi antiguo professor 'my former professor' and la catedral antigua 'the old cathedral').

\section{B. Non-transfer and Discourse-level Issues (Typical among Some Heritage and Advanced Non-heritage Learners)}

Unlike transfer errors, issues at the level of discourse are less dependent on the level of proficiency of the writer and tend to have more to do with more abstract qualities, such as creativity, approach, and polish.

1. Repetition and redundancy-One writing pitfall that commonly goes unnoticed when the focus of the student is on structure and grammaticality is the repetition of nouns, verbs, or adjectives that can make an essay sound highly redundant. Many students continue to use the same words to express the same thought or idea throughout their composition. These can be words such as incendio 'structure fire' or mascotas 'pets' in compositions about these topics, or even simple verbs that also typically get repeated throughout, such as tener 'have'. One thing I ask students to do is to read their composition aloud to themselves and to think what it would sound like if it were written in their first language. It is then that they realize just how simplified their composition sounds. At this point I suggest students think of synonyms that work just as well and to alternate these to add some variety to the vocabulary of their essays. One way students can improve their essays and make them more interesting is to do a prewriting step that entails brainstorming and looking for synonyms or paraphrases that they can use to vary the ways in which they express the same topic throughout their writing. Likewise, heritage learners should consider exploring other ways of saying what they would normally use in everyday conversation. 
2. Creativity-Related to the preceding category, another way students can make their essays more interesting is to be creative about how they approach a topic or express an idea. For example, a composition about dogs can become rather boring if the word dog is used throughout, however, by adding some colorful alternate words or expressions, like "man's best friend," or "little hairy companion," both of which have near equivalents in Spanish can significantly improve an essay. Or imagine you are writing about something burning in a house fire you can express this notion with las llamas "flames" or infierno "hell." Another way to make a composition less predictable and more entertaining for the reader is for a student to experiment with point of view. For example, when writing a personal narrative, it is customary to write in the first person. One exercise students find interesting is the rewriting of a personal account in the third person. This is a good way to make students understand the third person omniscient perspective. Alternatively, switching the point of view of a composition to the first person and writing on behalf of the protagonist can render equally fascinating effects, also making an essay more pleasant to read.

3. Variety in sentence length-Some students think that if they keep their sentences short they will generate fewer errors. While this can be true, writing shorter sentences can also have the additional effect of making an essay sound simplistic and even monotonous. Frequent short sentences have another side effect in making it necessary to repeat words throughout a paragraph.

4. Avoidance of stream of consciousness writing (unless appropriate)-The style of writing known as stream of consciousness is an organic type of writing that pays less or no attention to punctuation and can be quite effective when writing personal narratives, or when writing fiction, However, this type of writing, is not always practical for all writing assignments. The very nature and purpose of writing is to create a record for posterity and therefore, punctuation and clarity are necessary.

\section{Miscellaneous Orthographical or Editorial Mistakes}

One of the most important last steps before submitting any composition for a grade is to check for careless typographical/editorial mistakes such as capitalization, misspellings, repeated words, and missing or incorrect punctuation. This stage corresponds more to the traditional "proofreading" stage of compositions, and should be the absolute final step before submitting the written work.

1. Capitalization and spelling-Spanish does not capitalize nearly as often as does English. For example, days of the week, months and the names of languages or nationalities are not capitalized in Spanish.

2. Accents and other diacritical marks-English does not typically carry written accent marks and therefore students either do not use them or they do so inconsistently. The first category are monosyllabic words that carry an accent mark simply to distinguish them from homonyms spelled identically, but without the accent. Examples are más meaning 'more' as opposed to mas meaning 'but,' tú meaning 'you' as a subject as opposed to tu meaning 'your', or él meaning 'he', as opposed to $\boldsymbol{e l}$ meaning 'the'. In each case, when used the first way, these words are always accented. These words simply have to be memorized as having accents. The second category of accents are those required for words that are more than one syllable long. Spanish has very specific accent rules that must be memorized. It is because of the straightforwardness and rigidity of the written accent rules in Spanish, that when it is compared to other Romance languages such as Italian, it is much more predictable in terms of pronunciation.

3. Punctuation-All standard signs of punctuation that are used in English are the same ones that are used in Spanish. There are a few exceptions, however. For example, just as periods and exclamation and interrogative marks are used to mark the ends of sentences in English, they do so as well in Spanish. However, unlike English, Spanish also employs inverted exclamation and question marks at the beginning of these utterances as well. Students often forget this convention when writing in Spanish.

“Active" Versus "Passive" Writing: The Case for a Pre-submission "Peer Review and Self-evaluation Module"

Students approach compositions from a variety of perspectives and as suggested in the previous section, both L2 and HL learners tend to commit the same types of errors albeit in different distributions. Add to this other such variables as topic, style, genre, a student has so many factors to consider before finalizing a composition that is "ready" to submit. Although it is natural for an individual to be more careful with word choice, spelling, or grammatical constructions when writing, I have observed that students still manage do this in a more passive sense. In other words, many students, HLs and L2s alike, typically sit and type a composition in one sitting much in the way they would sit to compose a personal letter, writing what comes to mind without much forethought or planning. To make matters worse, these same students seldom apply stringent standards or specific criteria when returning to review and revise their own work, and much less when reviewing that of others. The result is self or peer feedback that is seldom adequate for students to be able to significantly improve their essays. ${ }^{6}$

\footnotetext{
${ }^{6}$ Language students are confronted with a dual challenge, a more basic one which is that of expressing oneself, and another which is more advanced, that of making a coherent argument. Additionally, one must remember that language is primarily an oral phenomenon (Azevedo 2008). Writing in both first and second language contexts, is a convention that is only learned with education after one first acquires the spoken language and a working knowledge of the grammar.
} 
The piece that appears to be lacking in the L2 writing process, even where student peer evaluation has been incorporated as an element toward the end of the process, is a step where students conduct a highly structured and informed self-evaluation of their writing prior to submitting it to either a peer or the instructor for a grade.

What if students could be trained to take a more active stance in the evaluation process not just toward their own compositions but when evaluating essays written by others as well? The truth is that writing in any language, including Spanish, is somewhat of an art, and if provided some additional tools to approach the task more actively, with both demonstration and practice of how this should be done, students can improve their writing significantly. ${ }^{78}$

What is proposed here is an enhancement to the $\mathrm{L} 2 / \mathrm{HL}$ student composition writing process that integrates a multiphased module for peer and self-evaluation of student compositions as a process that takes place not only at the end of each composition, but rather throughout the entire semester, beginning with comprehensive demonstration and training of the proposed method by the instructor, followed by practical application with exercises, and ending with full implementation on actual compositions. The flowchart in Figure 4 illustrates how this new module can be inserted into the writing process of existing $\mathrm{L} 2 / \mathrm{HL}$ composition classes that may or may not currently have a peer evaluation component already built in.

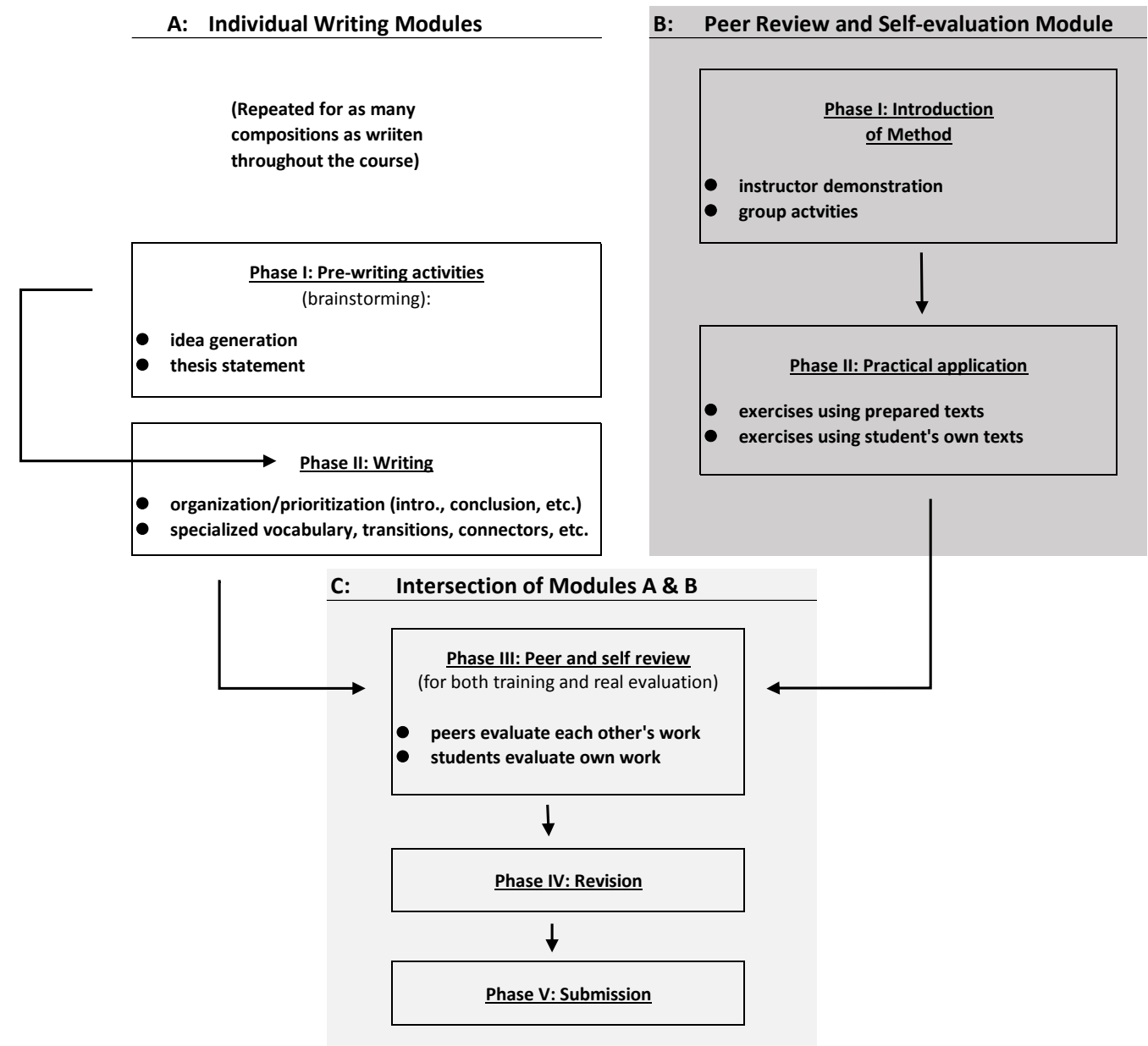

Figure 4: Flowchart representing integration of the "Peer Review \& Self-evaluation Module"

Figure 4 shows how a semester's work can be divided into three categories: A. Individual Writing (IW) Modules; B. the Peer Review \& Self-evaluation Module; and C. Intersection of Modules A \& B (Implementation):

Category A, or "Individual Writing Modules," corresponds to the various compositions that are traditionally assigned to students for a grade over the course of a semester and so the module repeats throughout the semester for as many compositions as are assigned. Phases I and II under Category A are unshaded in the figure because they are essentially

\footnotetext{
${ }^{7}$ Active writing here does not refer to the avoidance of passive voice when writing as in Conroy (2019), but rather taking a more active role in looking for and addressing certain errors before submitting a composition.

${ }^{8}$ One might consider this step as a type of bookend to the initial brainstorming or fact-finding stage that the student may initiate before sitting down to write the first draft of a composition. Just as one during this initial phase would consider such options as a thesis statement, vocabulary, organization and prioritization of ideas, the proposed prefinal stage would likewise include a list of items. The difference between the brainstorming stage and this one is that this one would be much more specific in terms of the items that one would "check" to ensure the composition is ready to submit.
} 
the same as the prewriting and writing phases that one would find in traditional composition classes. In order to understand what happens after Phase II within this module, it is first necessary to explain Category B. Peer Review and Self-evaluation Module (here represented by the darker grey shading).

Category B, or "The Peer Review and Self-evaluation Module," is an innovation that this paper proposes to integrate into the existing composition course, as a semester-long process that provides students with tools necessary for the active review of their own or others' compositions. Phase I of the module begins at the very beginning of the semester, well before compositions (of Category A) are ever written and introduces both the criteria and the method that students would use throughout the semester to evaluate each composition assigned. Among the first tools that the instructor would share during this phase are checklists of specific problems and issues that students should look for in a structured fashion when reviewing any piece of writing in the L2. The ideal checklist would consist of items that are found regardless of the type of essay written. At this stage, the instructor would demonstrate step-by-step how to go about using the checklists provided during the review process. At this point the instructor would also conduct group activities to ascertain the student's understanding of the method, as well as to reinforce certain items that students find difficult to discern. Phase II of this module continues to develop abilities and sensitivities to some of the more common composition pitfalls by assigning and reviewing a number of exercises where students have to identify the errors of both prepared texts as well as their own. Once students are comfortable with the tools, method, and practical application, they are then ready to move on to Phase III where they will implement these new skills.

Category C. Intersection of Modules A \& B (represented by the lighter shade of gray in the figure), is the point at which both modules of this integrated writing program overlap and where implementation of what students have been practicing in Module B finally takes place with the review of compositions actually written for a grade. Category C consists of Phases III, IV, and V, each corresponding respectively to the activities of peer and self-review, revision based on these reviews, and final submission. In other words, Phases III, IV, and V resume where Phase II in both Categories A and B end.

\section{Checklists for Use with Peer Review and Self-evaluation of Spanish Compositions}

The previous section discussed the need for two checklists that could be used as criteria for the review of student compositions under Category B. The Peer Review and Self-evaluation Module of Figure 4. Figures 5 and 6 are such checklists for potential use in Spanish composition classes. Both instruments take into account data and observations from Ryan (2018), as well as additional data from the same 2017-2018 study that produced Ryan (2018) but, for reasons cited previously, were not reported in that paper. In other words, the categories of errors that are included as criteria for review in Figures 5 and 6 are based on authentic, combined L2 and HL student data.

Moreover, both instruments have been designed to be analogous to the L1/HL/L2 continuum in Figure 1, in that earlier items in Figure 5 are more remedial for L2 or HL students still working out grammatical and transfer issues. Intended to be used consecutively, both checklists cover a wide range of writing pitfalls from less to greater complexity. Depending on where a student lies on the L2 or HL learner continuum in Figure 1, s/he can either start at the very beginning of Figure 5 or somewhere further down the list. It is recommended that the student use Figure 5 first to identify grammatical errors and to then move to the second checklist in Figure 6 which deals with higher-level discourse issues and makes recommendations for improvement in terms of style, creativity, and flow. 


\begin{tabular}{|c|c|c|}
\hline & & $\nabla$ \\
\hline 1) & $\begin{array}{l}\text { All adjectives/articles should agree in gender and number with their nouns. } \\
\text { (INCORRECT: un casa bonito }\end{array}$ & \\
\hline 2) & $\begin{array}{l}\text { All conjugated verbs should agree with their subjects in person and number. } \\
\text { (INCORRECT: nosotros estudias } \\
\text { CORRECT: nosotros estudiamos) }\end{array}$ & \\
\hline 3) & $\begin{array}{l}\text { Definite articles are used to express general things in Spanish. } \\
\text { (INCORRECT: Me gusta pan } \\
\text { CORRECT: Me gusta el pan.) }\end{array}$ & \\
\hline 4) & $\begin{array}{l}\text { Subject pronouns are only used to clarify. They are not always required like English. } \\
\text { Their overuse can make your Spanish sound redundant. } \\
\text { (UNLIKELY: Ella ha visto al chico. } \\
\text { LIKELY: } \boldsymbol{H a} \text { visto al chico. ) }\end{array}$ & \\
\hline 5) & $\begin{array}{l}\text { The personal "a" is required before direct objects that are persons or pets. } \\
\text { (INCORRECT: María quiere su mamá. } \quad \text { CORRECT: María quiere a su mamá.) }\end{array}$ & \\
\hline 6) & $\begin{array}{l}\text { The subjunctive mood is required after most impersonal expressions and statements of } \\
\text { doubt, volition, or contrary to fact. } \\
\text { (INCORRECT: Es importante que vienes. CORRECT: Es importante que vengas. ) }\end{array}$ & \\
\hline 7) & $\begin{array}{l}\text { The Imperfect tense is used to narrate background information in the past while the } \\
\text { preterit is used to convey individual past actions. } \\
\text { (INCORRECT: Llovió mucho cuando llegué. CORRECT: Llovía mucho cuando llegué.) }\end{array}$ & \\
\hline 8) & $\begin{array}{l}\text { Some Spanish structures do not take prepositions as they might in English. } \\
\text { (INCORRECT: Todos de mis amigos } \\
\end{array}$ & \\
\hline 9) & $\begin{array}{l}\text { Some Spanish verbs take prepositions while they do not in English. } \\
\text { (INCORRECT: ayudar hacer algo } \quad \text { CORRECT: ayudar a hacer algo) }\end{array}$ & \\
\hline 10) & $\begin{array}{l}\text { Spanish adjectives are usually placed after the noun. } \\
\text { (INCORRECT: sucias manos } \\
\text { (INORRECT: manos sucias) }\end{array}$ & \\
\hline 11) & $\begin{array}{l}\text { The verbs ser/estar/haber all mean "to be" in different ways. } \\
\begin{array}{ll}\text { (INCORRECT: Lo es escuchando. } & \text { CORRECT: Lo está escuchando) }\end{array}\end{array}$ & \\
\hline 12) & $\begin{array}{l}\text { The prepositions por and para both mean "for", but in different ways. } \\
\text { (INCORRECT: Gracias para el regalo. CORRECT: Gracias por el regalo.) }\end{array}$ & \\
\hline 13) & $\begin{array}{l}\text { The pronouns tú and usted both mean "you" but in different situations. } \\
\text { (INCORRECT: Señor Gómez, ¿estás tú listo? CORRECT: Señor Gómez, ¿está Vd. listo?) }\end{array}$ & \\
\hline 14) & $\begin{array}{l}\text { Some expressions don't translate into Spanish from English and require a new structure. } \\
\text { (INCORRECT: Estaba terminado. } \\
\text { CORRECT: Había terminado.) }\end{array}$ & \\
\hline 15) & $\begin{array}{l}\text { Single syllable words that have a written accent have different meanings from the same } \\
\text { words written without an accent (e.g., él/el, más/mas, tú/tu, etc.) } \\
\text { (INCORRECT: Mario quiere mas. } \\
\text { CORRECT: Mario quiere más.) }\end{array}$ & \\
\hline 16) & $\begin{array}{l}\text { Direct, indirect, and reflexive pronouns are used and positioned correctly. } \\
\text { (INCORRECT: Regalé lo a Tomás. } \\
\end{array}$ & \\
\hline 17) & $\begin{array}{l}\text { Check for careless typographical/editorial mistakes such as capitalization, misspellings, } \\
\text { repeated words, and missing or incorrect punctuation. } \\
\text { (INCORRECT: Paco habla Español. } \\
\text { CORRECT: Paco habla español.) }\end{array}$ & \\
\hline 18) & $\begin{array}{l}\text { Spanish uses inverted question marks and exclamationation points to mark the } \\
\text { beginning of a question or an exclamation. } \\
\text { (INCORRECT: Qué quieres? CORRECT: ¿Qué quieres?) }\end{array}$ & \\
\hline
\end{tabular}

Figure 5: Checklist for peer and self-evaluation of transfer and other grammatical errors (common among second language and some heritage learners) 


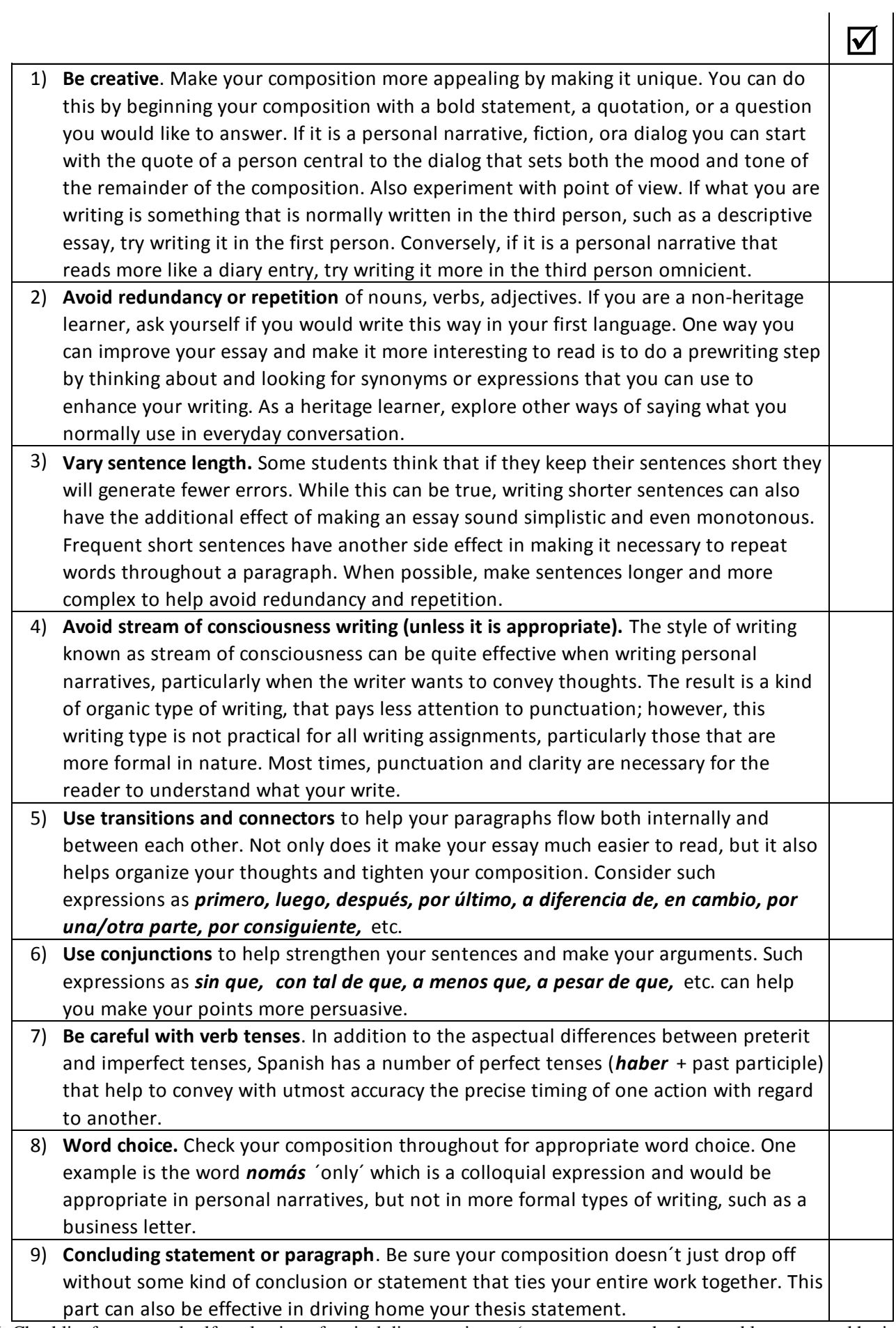

Figure 6: Checklist for peer and self-evaluation of typical discourse issues (common among both second language and heritage learners)

\section{CONCLUSIONS}

The goals of this paper were twofold: The first was to build on the work of a previous paper (Ryan 2018) that proposed strategies that fellow teachers of Spanish composition might implement in combined classes of HL and L2 student learners. Conversely, the aim of this paper was to shift the focus from teacher to student, and in addition to the recommendations made in Ryan (2018), introduces the notion of an active writing program for students, offering a new semester-long module that provides students with criteria and training to become better peer reviewers and selfevaluators of their own writing. In other words, to reiterate assertions by Nas and van Esch (2014), the ultimate goal of any composition instructor is to provide students the tools they need to become better evaluators of their own writing.

The advantages of the proposed method are several. First, it returns control to students by providing a pre-determined inventory of error categories the students can use to evaluate their compositions before sharing them with a peer or their 
instructor. Secondly, application of the proposed module makes the student self-reliant and empowers them. In this sense, although the intention of the module is for the student to conduct better evaluations of their own writing, once a student is trained, the same instrument should also then be used to guide what specific types of errors to look for when evaluating the work of a classmate.

Finally, and in conclusion, it is also suggested that with continued use of the module, the student will begin to incorporate this phase into their normal routine before submitting future compositions. In other words, it will essentially condition the student to more thoroughly "check" for certain things when s/he is approaching the final stages of writing. Of course, an ultimate goal for more advanced students might be that they start to incorporate some of the evaluation criteria proposed here even before reaching the peer review/self-evaluation stage, essentially making items on the proposed checklists not only ones they must return to when checking previously written work, but rather also things to consider, or in some cases avoid, during the writing process itself.

\section{REFERENCES}

[1] Azevedo, Martín. (2008). Introducción a la lingüística española. New York, NY: Pearson.

[2] Brinkman, Arnoud. (2003). La eficacia del feedback de alumnos sobre los textos argumentativos de sus compañeros. Master's thesis. Nijmegen: Radboud University.

[3] Camacho, José. (2018). Introducción a la sintaxis del español. Cambridge: Cambridge University Press.

[4] Chaudron, Craig. (1984). "The Effects of Feedback on Students' Composition Revisions." RELC Journal, 15(2): 1-15.

[5] Conroy, Gina. (2019). “Active vs. Passive Writing.” 2019 Write Well Sell Well Retreat. Writercon 2019 blog https://www.writewellsellwell.com/2017/12/active-vs-passive-writing/ (accessed 7/15/19).

[6] Cotterall, Sara \& Robin Cohen. (2003). "Scaffolding for Second Language Writers: Producing an Academic Essay." ELT Journal, 15(2): 158-166.

[7] Ferris, Dana R. (2004). "The Grammar Correction Debate in L2 Writing: Where Are We, and Where Do We Go from Here? (and what do we do in the meantime?)." Journal of Second Language Writing, 13(1): 49-62.

[8] Hyland, Ken \& Fiona Hyland. (2006). "Feedback on Second Language Students Writing.” Language Teaching, 39: 83-101.

[9] Liu, Jun \& Jette G. Hansen. (2002). Peer Response in Second Language Writing Classrooms. Ann Arbor, MI: University of Michigan Press

[10] Nas, Marly \& Kees van Esch. (2014). “Acquisition of Writing in Second Language Spanish.” In Geeslin, Kimberly (ed.), The Handbook of Spanish Second Language Acquisition, First edition. Hoboken, NJ: John Wiley \& Sons, Inc.

[11] Ryan, John M. (2018). "Spanish Composition Errors from a Combined Classroom of Heritage (L1) and Non-heritage (L2) Learners: A Comparative Case Study.” Journal of Language Teaching and Research 9 (3): 439-452.

[12] Truscott, John. (2007). "The Effect of Error Correction on Learner's Ability to Write Correctly." Journal of Second Language Writing, 16(4): 255-272.

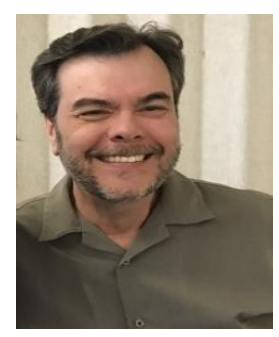

John M. Ryan earned his Ph.D. in Rhetoric, Composition, and Linguistics at Arizona State University in Tempe, Arizona, USA in 2008. He earned his master's degree in Spanish linguistics, also from Arizona State, in 1991. He earned his Bachelor of Science degree in Spanish from Georgetown University's School of Languages and Linguistics in Washington, D.C. in 1985.

$\mathrm{He}$ is currently Associate Professor of Spanish Linguistics at the University of Northern Colorado. His research on the acquisition of verbs by children and adults has been published in such journals as the Journal of Child Language and Development, Teaching and Practice in Language Studies and Hispania, and his first book, The genesis of argument structure: Observations from a child's early speech production in Spanish (Germany: Lambert, 2012), traces the emergence of the verb phase in the developing language of a monolingual child learning Peninsular Spanish. Other interests include historical news discourse of the Italian American community and the reconstruction of proto Ibero Romance, for which he has recently authored several scholarly papers for different edited volumes and is working on his second book.

Dr. Ryan is a member of the Linguist List International Linguistics Community, the Societas Linguistica Europaea, the Linguistic Society of America, the Rocky Mountain Modern Language Association, the Linguistic Association of the Southwest, the National Italian American Foundation, and the Italian American Historical Society. 